\title{
Paste backfill system design and commissioning at Chambishi Copper Mine
}

\author{
AX Wu University of Science and Technology Beijing, China \\ XX Miao University of Science and Technology Beijing, China \\ XH Liu University of Science and Technology Beijing, China \\ YM Wang University of Science and Technology Beijing, China \\ CL Wang Africa Mining PLC of China Nonferrous Metals Co. Ltd., Zambia \\ JJ Zhang Africa Mining PLC of China Nonferrous Metals Co. Ltd., Zambia
}

\begin{abstract}
West orebody is now the main production zone of Chambishi Copper Mine. Upward drift stoping is performed to meet the annual ore production of more than $1 \mathrm{Mt}$. Cemented classified tailings backfill was originally employed, which then proved to be both economically and operationally impractical due to high cement cost, low metal recovery, severe backfill tailings shortage, etc. As an alternative, the current paste backfill system with low cement addition was suggested after a comprehensive study and investigation. Construction work of the paste backfill system started in 2012. The system was put into production at the beginning of 2014 after commissioning. During commissioning, the backfill system reached a capacity of $60 \mathrm{~m}^{3} / \mathrm{h}$ with the paste concentration of 68 to $70 \%$, and the friction loss of the pipeline transport was 4-6 MPa/km. To meet the backfill strength, the cement to tailings ratio for primary stopes was 1:12, and 1:30 for secondary stopes. As a result, the composite cost for backfill was only USD 15 to $20 / \mathrm{m}^{3}$, while ore recovery increased by $35 \%$ and mining to cutting ratio dropped by $80 \mathrm{~m}^{3} / \mathrm{kt}$. Since commissioning investigations indicate that this paste backfill system will be capable of prolonging west orebody's service by about 10 years, and will bring about enormous economic returns.
\end{abstract}

This paper presents the case study of the highly automated system and its commissioning performance, with emphasis on key processes including unclassified tailings thickening, two-stage slurry mixing, paste pumping, and underground backfill.

\section{Introduction}

Located in the middle of the Zambia Copper Zone, Chambishi Copper Mine was originally owned by Zambia Consolidated Copper Mines Limited (ZCCM Ltd). The open pit mining at Chambishi Copper Mine commenced in 1965, which was then transferred to underground operation in 1975. Mining operations, ceased in 1987, and in 1998 the operations were taken over by the NFC Africa Mining Plc. formed by China Non-ferrous Metal Mining Co., Ltd. and ZCCM. Currently the deposit is made up of three ore bodies - the main, the west and the lower - with the west orebody being the main production area. Chambishi Copper Mine holds a reserve of more than $29 \mathrm{Mt}$ of ore with an average copper grade of $2.69 \%$. An annual production capacity of over $2 \mathrm{Mt}$ of ore is achieved at Chambishi, and the copper production is 30,000 t/a.

As the main production area, the west orebody contributes approximately $1 \mathrm{Mt}$ of ore to the total production annually. The dip of west orebody is $30^{\circ}$, and the average thickness is $7.36 \mathrm{~m}$. Upward drift stoping and filling is the mining method performed at the west orebody. Originally, cemented classified tailings with mass fraction of $60 \%$ were used to fill the goafs. However, the classified tailings backfill proved to be an unsuitable filling method at Chambishi for the following reasons:

- The milled tailings are too fine to produce enough classified tailings. The $-74 \mu \mathrm{m}$ particles account for about $70-75 \%$ of the total tailings, rendering only $30 \%$ of the total tailings suitable for 
classified backfill. A particle size analysis of the Chambishi's processed tailings is illustrated in Table 1.

- Classified tailings backfill generally requires a high cement consumption, and the local cement price (USD $200 / t$ ) is too high to make the backfill expense acceptable.

- Too many pillars were left unmined in an attempt to reduce shear strength needed in the backfill and hence the cement consumption and as a result the ore recovery was barely $55 \%$.

- The classified tailings backfill leached too much water into the stopes of the mine; the surrounding rock is of poor quality which loses strength when wet and the open stopes became unstable. Ultimately even drainage of the stopes became costly.

Therefore, to improve mining recovery and bring down the cost of filling stopes, this classified tailings backfill system had to be revamped.

Table 1 Particle-size distribution of Chambishi's processed tailings

\begin{tabular}{cccccccc}
\hline Size/mesh* & $\mathbf{- 4 0 0}$ & $\mathbf{+ 4 0 0 - 3 2 0}$ & $\mathbf{+ 3 2 0 - 2 0 0}$ & $\mathbf{+ 2 0 0 - 1 4 0}$ & $\mathbf{+ 1 4 0 - 1 0 0}$ & $\mathbf{+ 1 0 0 - 8 0}$ & $\mathbf{+ 8 0}$ \\
\hline Proportion & 46.98 & 6.37 & 17.495 & 16.575 & 8.26 & 3.985 & 0.335 \\
Accumulation & 46.98 & 53.35 & 70.845 & 87.42 & 95.68 & 99.665 & 100 \\
\hline
\end{tabular}

* This particle size analysis was obtained using American standard sieves. According to US standardised sieve mesh dimensions, 200 mesh equals to the sieve size of $74 \mu \mathrm{m}$.

Favoured by advantages such as high slurry concentration, high tailings utilization, and low cement consumption, paste has gained increasing popularity in the mining industry as an alternative to conventional backfill (Liu \& Cai 1998; Ma et al. 2014); and became the preferred choice of backfill for Chambishi Copper Mine. Following extensive experimental investigation and verification, Chambishi finally introduced paste backfill in 2012. By the end of 2013, the backfill plant (Figure 1) was in production following the completion of construction and commissioning.

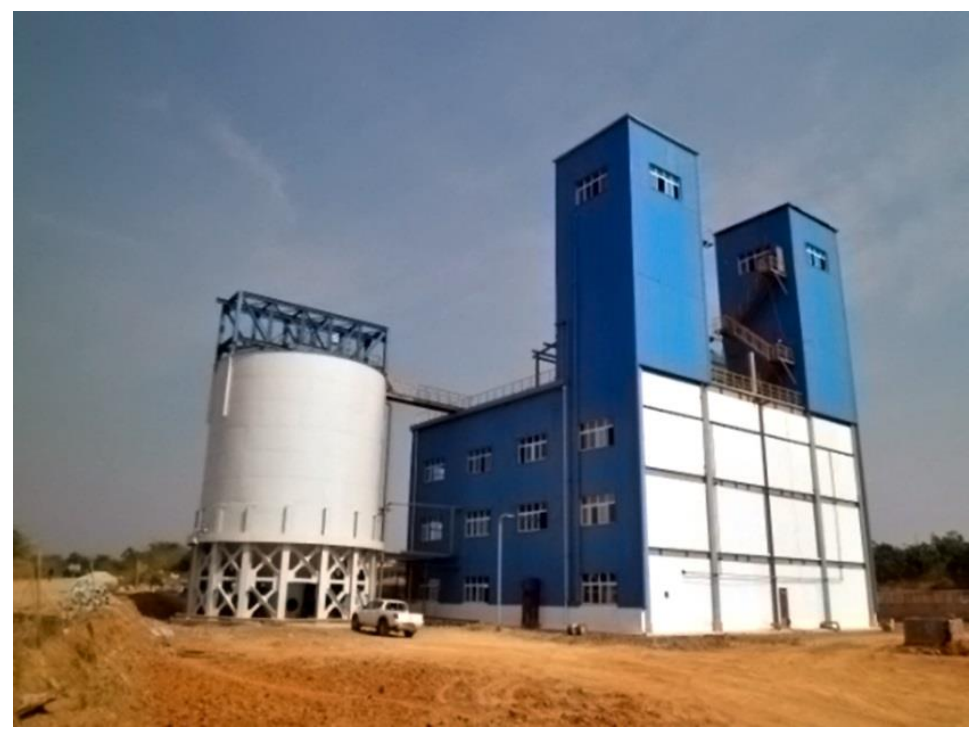

Figure 1 Overview of the paste plant at Chambishi

\section{Paste system design}

\subsection{System design considerations}

Paste backfill has been adopted at quite a few mine sites in China. Predecessors such as Jinchuan Group, Daye Nonferrous, and Chihong $\mathrm{Zn} \&$ Ge conducted substantial tests on tailings dewatering, cement 
addition, paste mixing and pumping (Wang et al. 2009) and significant breakthroughs have been made. Chambishi's paste system design borrowed many of the technical experiences from those successful operations.

In terms of tailings dewatering, prevailing techniques include two-stage dewatering using high efficiency thickener and vacuum filter, and one stage thickening using a deep cone thickener (DCT). However, the two-stage dewatering usually ends up with high expense, high energy consumption, and low system reliability when dealing with large amount of fine materials (Yang et al. 2014; Feng 2009). Since the tailings from Chambishi's processing plant contains more than $70 \%$ of $-74 \mu \mathrm{m}$ particles, a DCT proved to be the most suitable dewatering device to utilize the local tailings. Furthermore, DCTs have made an excellent debut in China at Chihong Zn\&Ge, not only simplifying the intricate traditional dewatering procedure, but also ensuring a satisfactory underflow concentration (Liu et al. 2009).

Generally, paste contains a very significant proportion of fines, often with more than $50 \%$ finer than $20 \mu \mathrm{m}$, and the yield stress for mine fill paste can be as high as 250 to 800 Pa (Jewell \& Fourie 2006). Stirring of such viscous material and evenly distributing powdered cement into it is very difficult. The twostage continuous mixing technique was developed to cope with those slurries with poor mixing characteristics and is now very mature and widely adopted for paste mixing (Wang et al. 2009). Domestic manufactured twin screw continuous mixers are very competent to handle two-stage continuous mixing. They mostly have low energy consumption and a small footprint and moreover, are easy to control and clean. Cement is usually added in the form of dry powder to the mixer by a twin-screw conveyor and weighed by an orifice plate flowmeter. With a stricter requirement on feeding control, more accurate weighing instruments like powder scale feeders have also been employed for cement addition (Ge 2013).

Paste can be transported to underground stopes by gravity flow or pumping. While pumping can ensure relatively high delivery pressures and constant flow rates, gravity flow is more economical for a delivery system with large gravitational potential. Chambishi's paste plant is located far from the stopes of the west orebody and its delivery system has a shallow pipeline gradient. Under these conditions, considerable pressure loss is to be expected during pipeline transport and hence the backfill system has been equipped with positive displacement (PD) pumps. The most common paste pump brands in the Chinese market are imported from manufacturers like Putzmeister (the PM and KOS series), Schwing (the KSP series), and GEHO (the DHC and DHT series); (Wang et al. 2002) though product series such as HBT60 and HGBS developed by domestic manufacturers are also reported to have good performance.

With all of the above taken under consideration, the paste backfill process at Chambishi was put forward as shown in Figure 2. The unclassified tailings from the processing plant will be delivered to the paste plant by slurry pumps, feeding through the top of the DCT. Tailings excess to those needed for backfill will be pumped to the TSF. After being thickened in the DCT, the tailings will be discharged from the bottom as high concentration underflow, which will then be pumped to the mixer. Dry cement powder stored in the cement silo will also be fed to the mixer with strict weight control by a powder scale feeder. Slag will be hauled to the paste plant and stored in a horizontal silo. Unlike cement, the weighing and feeding of slag will be completed by a disk feeder and a belt conveyor. Apart from thickened tailings, cement and slag, process water will be added to the mixer to adjust the paste slump. The two-stage mixing is crucial to produce paste with the desired strength and consistency. Ultimately, this paste will be transported by PD pumps through underground pipelines to the goafs. Each stage of the process is interlocked by the DCS, which is responsible for the monitoring, data collecting and regulating of most equipment and devices involved in the backfill system.

Chambishi's backfill system has two paste supply lines, each with a capacity of $60 \mathrm{~m}^{3} / \mathrm{h}$. Currently, only one supply line has been completed and the other line will be developed when mining production is further expanded. Meanwhile, because the slag source is not yet operating, the slag addition part is now lying idle. 


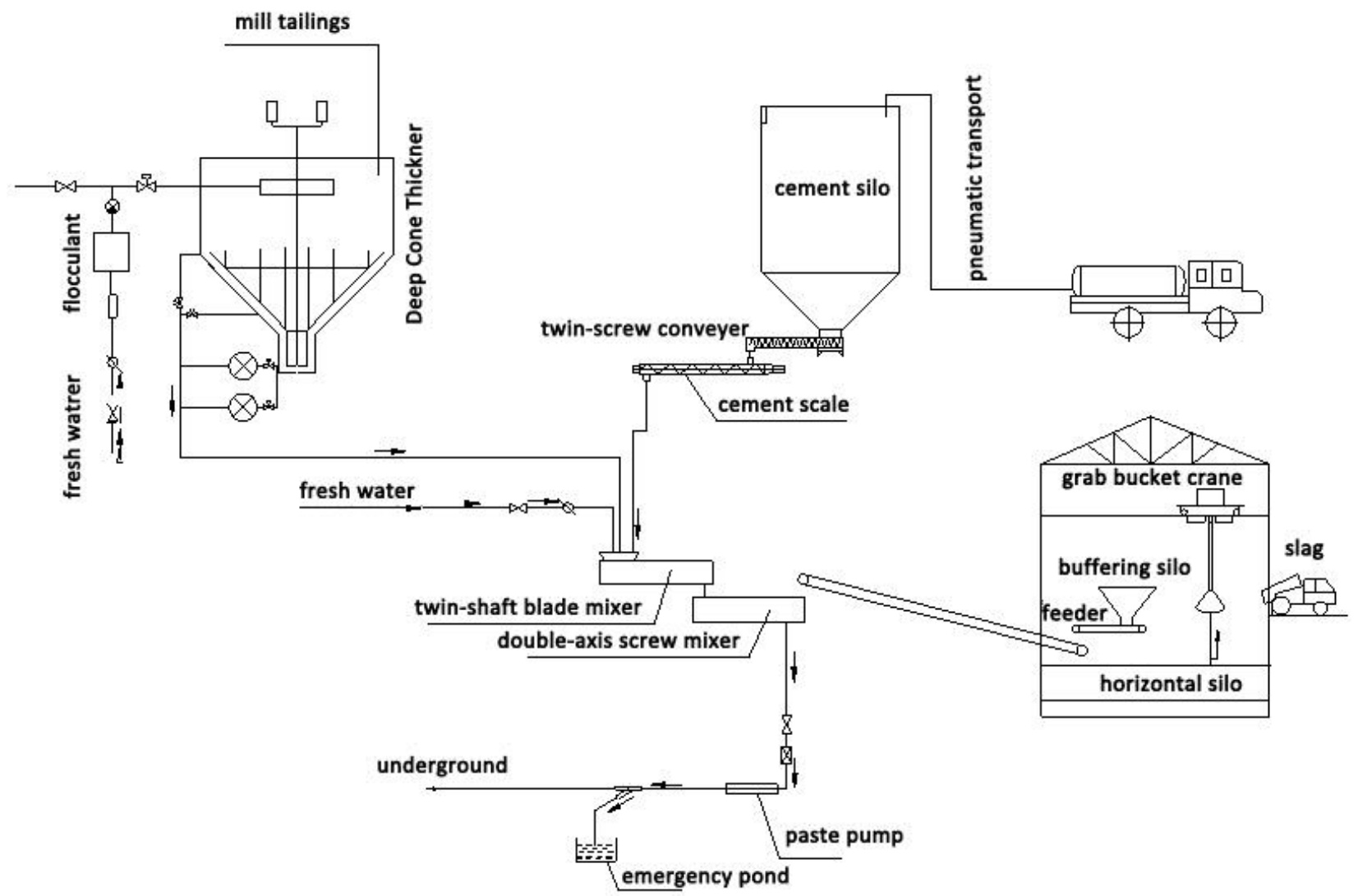

\section{Figure 2 Paste backfill process at Chambishi}

\section{$2.2 \quad$ Tailings thickening}

A Ф $16 \mathrm{~m}$ FLSmidth DORR DCT is employed for the thickening of mill tailings with a mass fraction of 10 to $25 \%$. The DORR is characterised in silhouette by a $30^{\circ}$ semi-cone angle, $11 \mathrm{~m}$ in height, and has an effective volume of $1,100 \mathrm{~m}^{3}$. Fitted with an E-Duc automatic feeding dilution system, the DORR is able to boost flocculating efficiency greatly while providing enough flocculating duration to secure floc quality. In case of excessive rake pressure and unstable underflow concentration, the DCT is capable of recycling, refluxing and diluting the underflow.

Another means of ensuring flocculating quality is with a Programmable Logic Controller (PLC) controlled flocculant dissolving and dosing apparatus (Figure 3). This apparatus is controlled by an ABB-eco PLC and EView touch panel controlling system through the coordinated operation of a flocculant powder feeding system, a flocculant solution stirring system, and a flocculant solution pumping system. As it is shown in Figure 3, the basic parts of the powder feeding system are a flocculant powder silo, a feeder, an air blower and a heater. Apart from the main stirring component, the solution stirring system has a $3 \mathrm{~m}^{3}$ mixing tank and a $6 \mathrm{~m}^{3}$ solution tank for temporary storage. The pumping system consists of a frequency controlled pump combo ( 3 pumps) and an electromagnetic flowmeter with a measuring range of 0 to $3 \mathrm{~m}^{3} / \mathrm{h}$.

During the commissioning operation, the anionic flocculant, Polyacrylamide, was added to the DCT with a dose of 0.02 to $0.05 \%$ mass fraction, or $30 \mathrm{~g} / \mathrm{t}$ dry tailings. The largest processing capacity achieved was $112 \mathrm{t}$ dry tailings/h, and the highest underflow mass fraction was $72 \%$. 


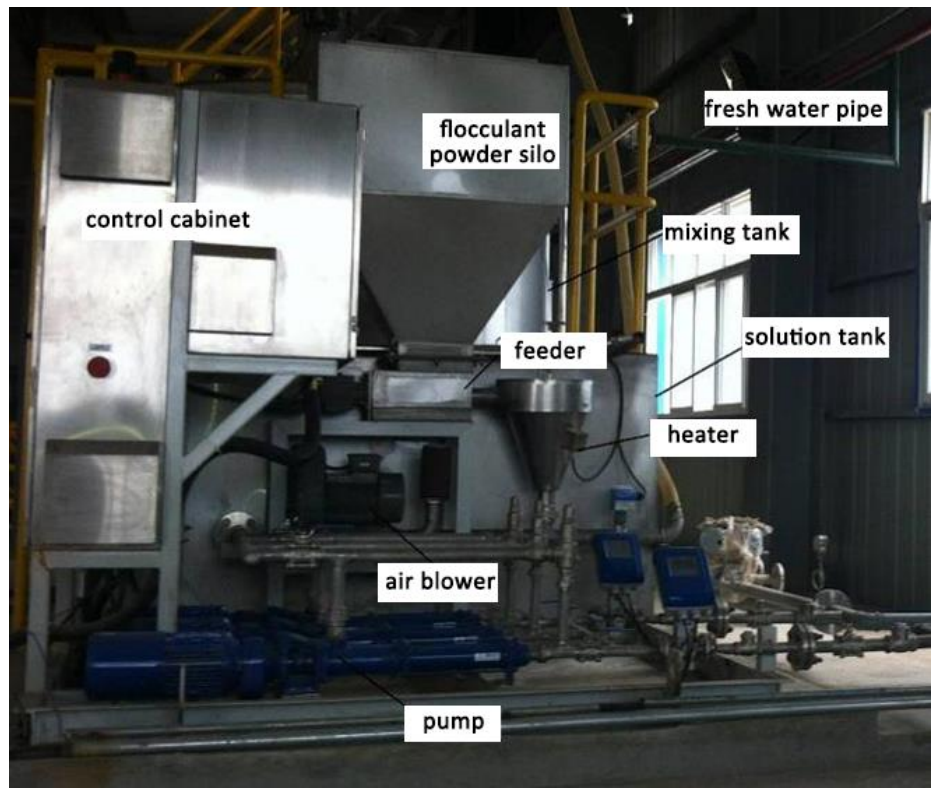

Figure 3 Flocculant dissolving and dosing apparatus

\subsection{Paste producing}

Thorough mixing of the paste materials, as well as accurate weighing and even feeding of cement, is crucial in producing a high-quality quasi-homogenous paste, which imposes better control systems on both the cement feeder and the paste mixer. The high accuracy powder scale feeder, comprised of even feeding device, gravity sensor weighing device and stable delivery device, is used to transport the cement stored in the $300 \mathrm{~m}^{3}$ silo to the mixer. The cement silo is equipped with a radar level indicator to make sure there is adequate cement supply. During commissioning, the powder scale was able to operate at a delivery rate of 3 to $33 \mathrm{t} / \mathrm{h}$ with a margin of error of $5 \mathrm{~kg} / \mathrm{h}$. Compared to the classic combination of twin-screw conveyor and plate flowmeter, the powder scale proved to have more reliable control and monitoring capabilities. In addition, the domestic XWSLJ-\$700 twin-screw continuous mixer, that has the ability to handle high viscosity materials at a processing capacity of $75 \mathrm{~m}^{3} / \mathrm{h}$, is utilised for the two-stage mixing of paste. The flux of thickened tailings is interlocked with the monitored fluid level by a tuning fork level indicator mounted on the secondary mixing tank, while the flux of processing water is regulated by a pneumatic valve that adjusts according to paste concentration estimated from the second-stage mixer's power consumption. The twin-screw continuous mixer layout is presented in Figure 4.

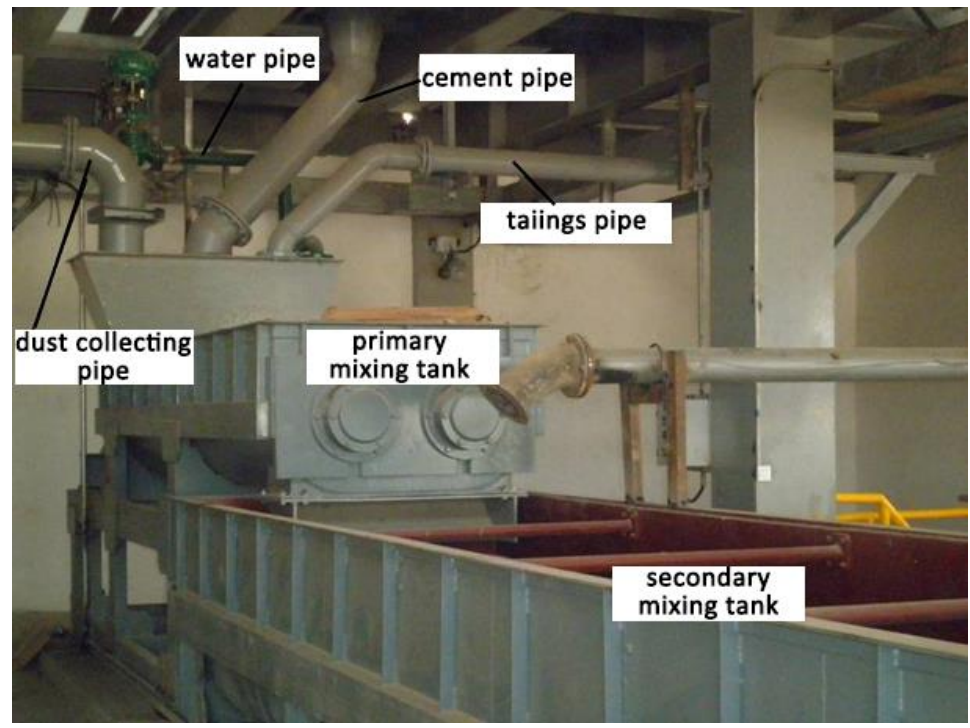

Figure 4 Layout of the twin-screw continuous mixer at Chambishi 


\subsection{Paste delivery system}

The goafs that need to be filled at the west orebody lie 100 to $300 \mathrm{~m}$ below the elevation of the paste plant, whilst the furthest goafs are located over $1300 \mathrm{~m}$ away from the paste plant, which means the deepest pipeline gradient is 7.73 . Under such circumstances, pumping remains the most favourable paste transport method. The Putzmeister high density solid pump, KOS 2180 HP, is used for paste transport. The KOS functions with a rated flow of $60 \mathrm{~m}^{3} / \mathrm{h}$ with normal working pressure of $6.9 \mathrm{MPa}$. Owing to its S-transfer tube, the valveless KOS is suited to deliver the high concentration paste continuously, and less obstructing and wearing are expected. Another KOS $2180 \mathrm{HP}$ pump is on standby to clean the clogged pipeline during the maintenance of the working pump. When the mining production scales up, both pumps will be put into production. Figure 5 illustrates the layout of the pumping units.

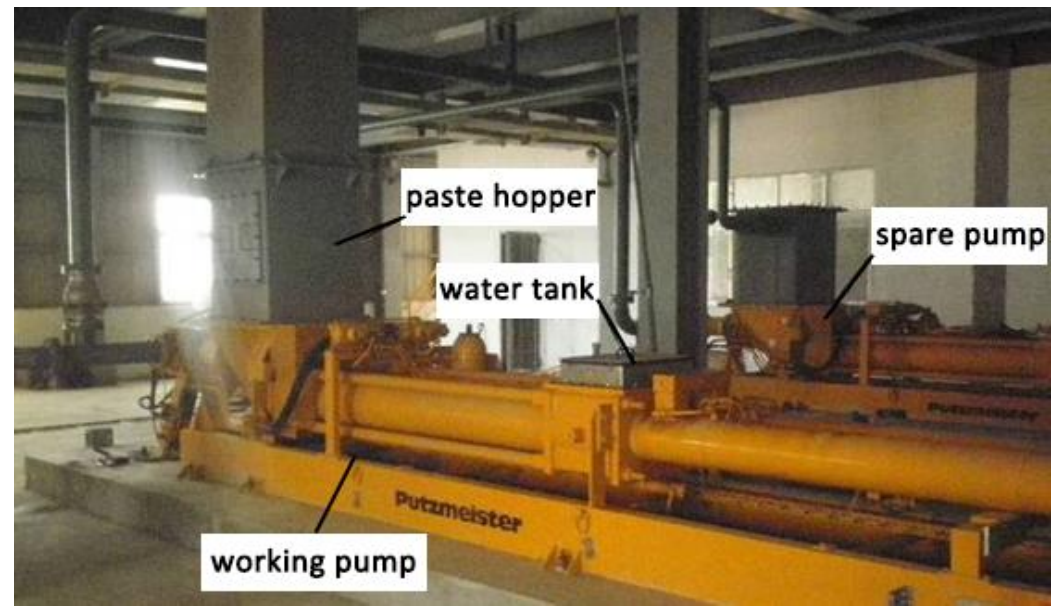

\section{Figure 5 Layout of the pumping unit at Chambishi}

With enhanced pressure head, the paste flows to stopes through the underground distribution system that consists of boreholes and pipes. A schematic diagram of Chambishi's distribution system is shown in Figure 6. At present, the $-216 \mathrm{~m}$ level is still under construction, the above levels are in filling operation. The borehole that reaches the $-110 \mathrm{~m}$ filling access is $220 \mathrm{~mm}$ in diameter, and protected by a $\Phi 159 \mathrm{~mm}$ (internal diameter) casing pipe, the space between external pipe and internal pipe is filled with $30 \mathrm{~mm}$ thick cement grouting. The horizontal pipeline is made of rubber lined steel pipes. The compressive strength of this $\Phi 121 \mathrm{~mm}$ (internal diameter) steel pipe is $4 \mathrm{MPa}$. The filling shafts are fitted with $\Phi 150 \mathrm{~mm}$ (internal diameter) seamless manganese steel pipes.

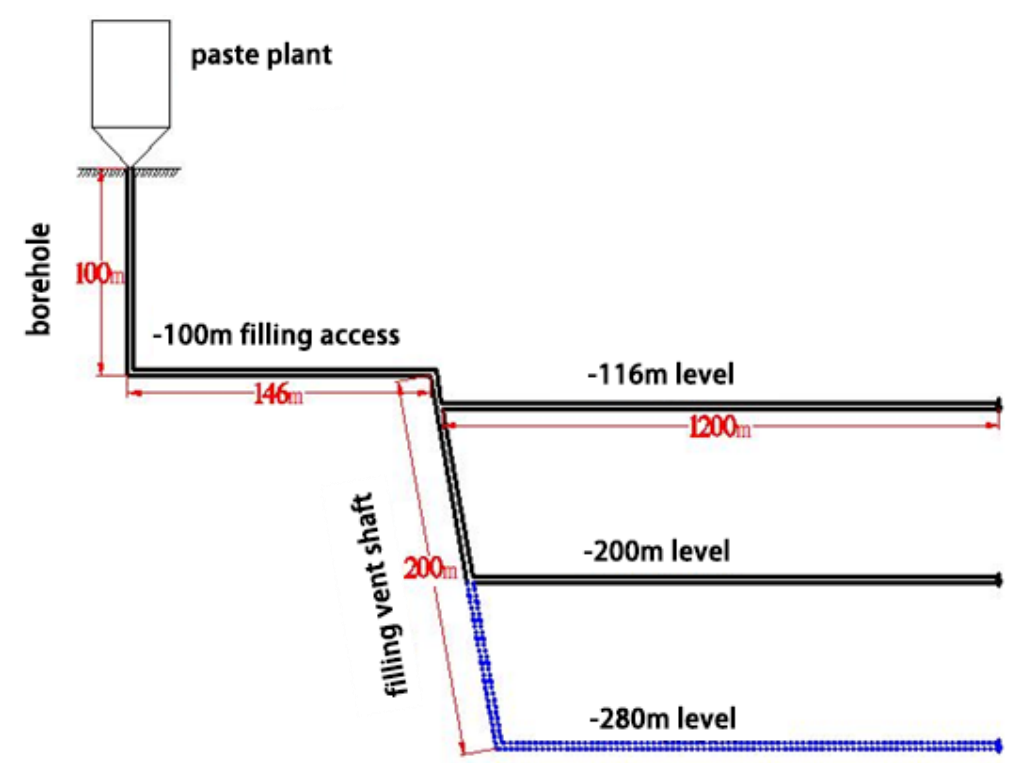

Figure 6 Underground distribution system 


\section{$3 \quad$ Underground backfill}

The current mining method at Chambishi is designed based on a level height of $60 \mathrm{~m}$, which is divided into five sub-levels. Each $12 \mathrm{~m}$ sublevel is then stoped every $4 \mathrm{~m}$ slice height. The stope design for paste backfill is shown in Figure 7. The width of each drift is $5 \mathrm{~m}$, and the length is equal to the orebody thickness. Primary drifts are mined from both wings to the middle. After the excavation of all primary drifts at a stope, the caves are filled simultaneously. With the same sequence, secondary drifts are excavated and filled. A Boomer 281 is employed for drilling; blasting is performed at every $3 \mathrm{~m}$ drilling depth; then the $4.3 \mathrm{~m}^{3}$ diesel LHD, ST710, is responsible for removing ore from the stope.

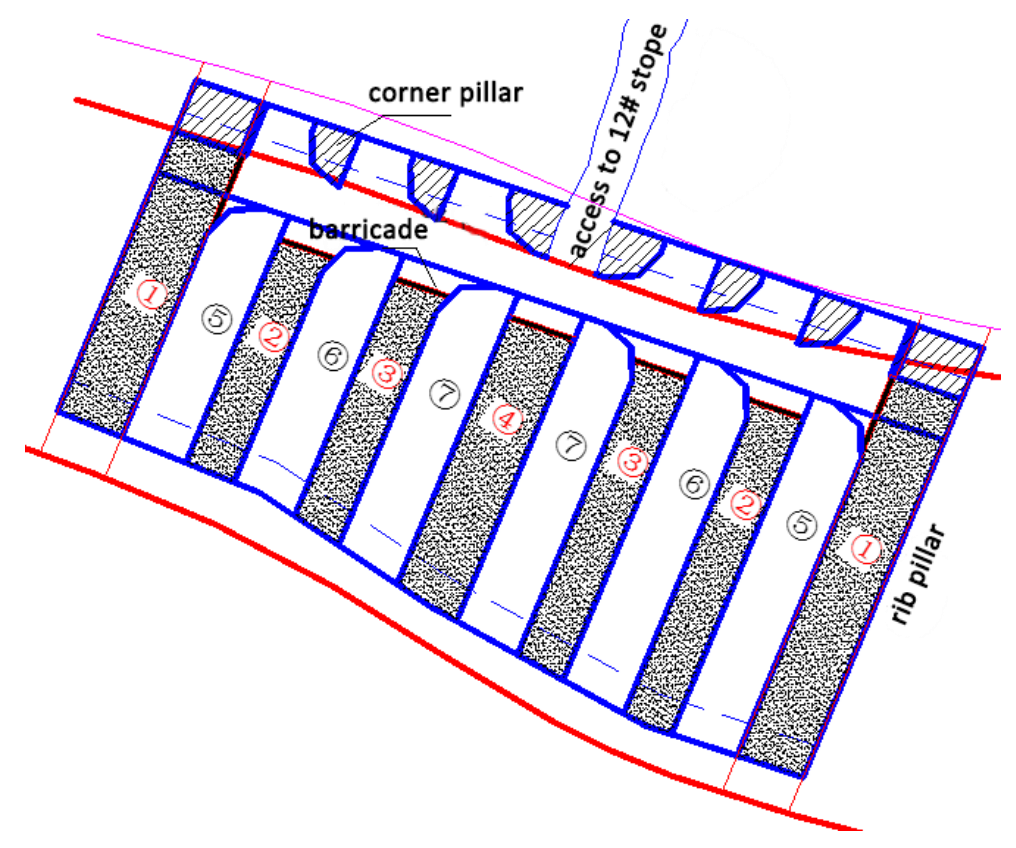

\section{Figure 7 Stope design for paste backfill}

The 12\# stope at the $-200 \mathrm{~m}$ level was selected as the pilot stope for backfill evaluation during commissioning. According to the data collected by the DCS, the solid mass fraction of paste slurry was 68 to $70 \%$; paste was delivered at a rate of approximately $1.5 \mathrm{~m} / \mathrm{s}$, or $60 \mathrm{~m}^{3} / \mathrm{h}$; pressure loss due to pipe transport friction was in the range of 4 to $6 \mathrm{MPa} / \mathrm{km}$. With a cement to tailings ratio of 1:12 for primary stopes and 1:30 for secondary stopes, it only took two days of curing before mining vehicles were able to operate on the backfill and less than 10 days to carry out blasting in the adjacent drifts, which significantly reduced the filling cycle. Due to the low water content of paste, backfill contraction and subsidence was almost eliminated; more than $80 \%$ of the backfill zones tested had tight contact with the roof. Since the introduction of paste backfill, the mining recovery increased from 55 to $90 \%$, the mining to cutting ratio dropped from 200 to $120 \mathrm{~m}^{3} / \mathrm{kt}$, even the cost for drainage and secondary support was reduced substantially. Moreover, the composite cost for paste backfill during commissioning operation was only USD 15 to $20 / \mathrm{m}^{3}$. It has been estimated that the production cost for copper will decline to about USD 270/t and that more than $8,000,000 \mathrm{t}$ of additional ore may be recovered to replenish west orebody's reserve, thus prolonging west orebody's service by approximately 10 years.

\section{Conclusion}

Compared with the classified tailings backfill, unclassified tailings paste backfill exhibits obvious advantages such as high tailings utility, high backfill strength, and low composite backfill cost. At Chambishi the simplified paste producing process using one stage DCT dewatering combined with two-stage continuous mixer mixing has proven to be not only have low energy consumption but is also very reliable. Chambishi's case could be a model reference for future paste backfill system designs. 
However, since the local cement price is relatively high, it is worthwhile to conduct more research on finding an appropriate source of slag, completing the slag addition plant, so as to further bring down the cost of backfill.

\section{References}

Feng, M 2009, 'Tailings thickening and surface disposal of paste tailings', Modern Mining, no. 10, pp. 82-86.

Ge, F 2013, 'Application and optimization of filling mining in Fengshan Copper Mine', Nonferrous Metals (Mining Section), vol. 65, no. 1 , pp. 20-23.

Jewell, RJ \& Fourie, AB (eds) 2006, Paste and Thickened Tailings - A Guide, 2nd edn, Australian Centre for Geomechanics, Perth, Western Australia.

Liu, TY \& Cai, SJ 1998, 'Status quo of application and research of paste fill technology in China and abroad', China Mining Magazine, vol. 7, no. 5, pp. 1-4.

Liu, XH, Wu, AX, Wang, HJ, Yan, QW \& Rong Y 2009, 'A primary discussion on the thickening law of paste-filling', Metal Mine, no. 9, pp. 38-41.

Ma, DJ, Wang, YM, Wu, AX, Ai, ChM, Yang, XX \& Zhou, FL 2014, 'Underhand drift paste backfill mining in broken and refractory mines', Metal Mine, no. 3, pp. 21-25.

Wang, HJ, Wu, AX, Xiao, WG, Zeng, PH, Ji, XW \& Yan, QW 2009, 'The progresses of coarse paste fill technology and its existing problem', Metal Mine, no. 11, pp. 1-5.

Wang, PX, Yuan, JQ \& Wang, WS 2002, 'Equipment selection of pumping paste filling', Nonferrous Mines, vol. 31, no. 1, pp. 10-12.

Yang, ZQ, Wang, YQ, Gao, Q, Chen, DX \& Yao, WX 2014, 'Technology reconstruction and application of the paste filling system to tailings in Jinchuan nickel mine', Nonferrous Metals Science and Engineering, vol. 5, no. 2, pp. 1-9. 